\title{
Double acceptor donor-acceptor alternating conjugated polymers containing cyclopentadithiophene, benzothiadiazole and thienopyrroledione: toward subtractive color organic photovoltaics
}

\author{
Shu-Wei Chang ${ }^{1}$, Tsuyoshi Muto ${ }^{2}$, Takeshi Kondo ${ }^{2}$, Ming-Jhih Liao ${ }^{1}$ and Masaki Horie ${ }^{1}$ \\ Double acceptor copolymers comprising benzothiadiazole (BT), thieno[3,4-c]pyrrole-4,6-dione (TPD) and two \\ cyclopentadithiophene (CPDT) units, and a series of copolymers comprising CPDT-A-CPDT (A: acceptor = BT or TPD) with \\ different numbers of thiophene units have been synthesized by combinations of Suzuki and Stille coupling, direct arylation and \\ oxidative polymerization. Ultraviolet-visible absorption spectra and cyclic voltammograms were measured to compare the optical \\ and electrochemical properties of the polymers. The double acceptor copolymer exhibited hybridized features resulting from the \\ presence of both BT, as well as TPD. On the other hand, an increase in the number of electron donor units resulted in an \\ increase in the band gap for both the TPD and BT series. Organic photovoltaics (OPV) devices were fabricated using the \\ polymers and a fullerene derivative. These donor-acceptor alternating copolymers showed higher OPV performance (power \\ conversion efficiency $=3-4 \%$ ) than other polymers. The active layer comprising the double acceptor polymer and a fullerene \\ derivative showed subtractive color resulting from wide-range visible light absorption, which is advantageous for developing \\ transparent building-integrated OPVs. The OPV performance of BT-based copolymers synthesized via direct arylation was \\ comparable or lower compared with those prepared by conventional cross-coupling polymerizations.
}

Polymer Journal (2017) 49, 113-122; doi:10.1038/pj.2016.72; published online 14 September 2016

\section{INTRODUCTION}

Organic photovoltaic (OPV) materials comprising conjugated polymers have been regarded as promising candidates in the development of renewable energy sources owing to their potentially lower manufacturing costs using methods such as roll-to-roll printing. ${ }^{1-4}$ Flexible devices can be fabricated to provide a wide range of aesthetic applications because the appearance of the device can be tailored by altering the active materials. ${ }^{5-22}$ To tune the optical and electrical properties of the available active materials, new chemical motifs incorporating fused rings and alternating donor-acceptor (D-A) structures in the polymer chain have been designed and synthesized. ${ }^{5-22}$

Benzothiadiazole (BT) and its analogs have been used as electron acceptor groups in conjunction with various donor units such as cyclopentadithiophene (CPDT); compounds containing these acceptor groups exhibit lower-energy levels and a reduction in the band gap compared with other D-A alternating copolymers. ${ }^{23-29}$ Since the development of poly[4,4-bis(2-ethylhexyl)-4H-cyclopenta [2,1-b;3,4- $\left.b^{\prime}\right]$ dithiophene-2,6-diyl-alt-2,1,3-BT-4,7-diyl] (PCPDT-BT, Figure 1), one of the first efficient third-generation donor-type conjugated polymers, ${ }^{30-35}$ various new conjugated polymers applying D-A structures have been synthesized. These feature a lower-energy band gap to capture a wider range of the solar spectrum.

The thieno[3,4-c]pyrrole-4,6-dione (TPD) unit has also attracted considerable attention as an acceptor group in D-A alternating copolymers. ${ }^{36-39}$ An impressive power conversion efficiency (PCE) of $6.4 \%$ was reported using poly[2,6-(4,4'-dihexyl-4H-cyclopenta[2,1-b; 3,4- $\left.b^{\prime}\right]$ dithiophene-alt- $N$-alkylthieno[3,4-c]pyrrole-4,6-dione (PCPDTTPD, Figure 1). ${ }^{40-43}$ The strong electron-accepting ability of the TPD unit is derived from the presence of two carbonyl groups, lowering the energy of the highest occupied molecular orbital (HOMO) levels. In addition, the rigid coplanar structure of the thienopyrrole ring of TPD facilitates electron delocalization along a polymer main chain, as well as intermolecular and intramolecular interactions. Furthermore, various alkyl side chains can be introduced

\footnotetext{
${ }^{1}$ Department of Chemical Engineering, Frontier Research Center on Fundamental and Applied Sciences of Matters, National Tsing-Hua University, Hsinchu, Taiwan and ${ }^{2}$ LINTEC Corporation, Research Center, Saitama, Saitama, Japan

Correspondence: Professor M Horie, Department of Chemical Engineering, Frontier Research Center on Fundamental and Applied Sciences of Matters, National Tsing-Hua University, 101, Section 2, Kuang-Fu Road, Hsinchu 30013, Taiwan.

E-mail: mhorie@mx.nthu.edu.tw

Received 18 June 2016; revised 7 July 2016; accepted 8 July 2016; published online 14 September 2016
} 

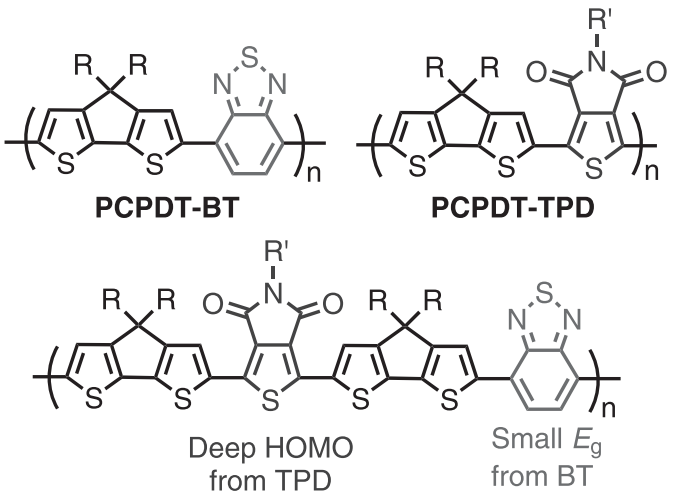

Double acceptor copolymer

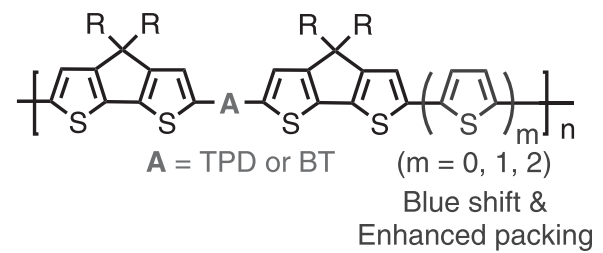

Copolymers comprising D-A-D with thienylenes

Figure 1 Polymers comprising cyclopentadithiophene, benzothiadiazole and thieno[3,4-c]pyrrole-4,6-dione. A full color version of this figure is available at Polymer Journal online.

at the nitrogen atom of TPD, leading to superior solubility and appropriate solution processability for device fabrication.

Of the two D-A polymers described above, PCPDT-BT exhibits a smaller energy band gap, that is, red-shift absorption in ultravioletvisible spectra, whereas PCPDT-TPD tends to show a lower-energy HOMO. ${ }^{5,30-35,40-43}$ On this basis, when BT and TPD are assembled together in a repeating polymer unit, we expect that the energy levels of the polymer could be tailored to give a wide photo absorption range with alterations to the TPD moiety, resulting in changes to the HOMO energy level and changes in the BT unit, resulting in the alteration of the absorption at higher wavelengths. While new D-A units and their combinations have been investigated, improved molecular designs incorporating further combinations of $\mathrm{D}-\mathrm{A}$ units are possible but have so far not been well-reported. Among them, double acceptor D-A alternating copolymers, a special form comprising the two types of acceptors and one type of donor in the main chain, have been rarely studied because of the tedious syntheses that are often required. Such double acceptor D-A alternating copolymers are mainly limited to diketopyrrolopyrrole-based polymers for use in OPVs and organic field-effect transistors. ${ }^{44,45}$ To understand the fundamental properties and obtain the desired chemical versatility expected for such double acceptor copolymers, further molecular design and synthesis are necessary.

Suzuki and Stille coupling polymerizations are often used for the synthesis of alternating conjugated copolymers. ${ }^{5,7,23,36,37,40-43}$ Despite the facts that the formation of aryl-aryl bonds is typically wellcontrolled and the yields in the elementary reactions are generally high, these coupling reactions possess several drawbacks: (i) numerous steps are required in monomer synthesis, (ii) the organometallic functional groups are unstable, (iii) the reactions result in the formation of stoichiometric amounts of toxic byproducts. On the other hand, direct $\mathrm{C}-\mathrm{H}$ arylation polymerization has attracted much attention because it presents an economically and ecologically attractive alternative to the traditional cross-coupling reactions. ${ }^{26-29,38,39,44-61}$ Recently, the application of directly arylated polymers to the preparation of OPVs has been investigated. ${ }^{45,54,55}$

In this study, we report the synthesis and characterization of double acceptor copolymers, -(CPDT-TPD-CPDT-BT $)_{n^{-}}$, comprising TPD, $\mathrm{BT}$ and two CPDT units in the polymer-repeating unit (Figure 1). To compare the optical and electric properties of the analogous polymers and better understand the influence of BT and TPD in the polymers, a series of copolymers comprising CPDT-A-CPDT (A: acceptor $=\mathrm{BT}$ or TPD) and thiophene or bithiophene units has also been prepared (Figure 1). The monomers and polymers were synthesized by combinations of palladium-catalyzed direct arylation, Suzuki coupling, Stille coupling and oxidative polymerization using iron(III) chloride. Ultraviolet-visible absorption spectra and cyclic voltammograms (CV) were measured to compare the optical properties and HOMO/LUMO levels of the polymers. These polymers were used to fabricate bulk heterojunction OPV devices with fullerene derivatives. Interestingly, the active layer comprising the double acceptor polymer with fullerene derivatives showed a subtractive color because of a wide-range visible light absorption, which is advantageous for the practical application of OPVs. Furthermore, OPV devices based on copolymers synthesized by direct arylation and other cross-coupling reactions are compared. This study focuses on materials composed of CPDT, BT, TPD and thiophene. Its results provide researchers insight into the effect of the double acceptors and the efficiency of directly arylated polymers in other material systems.

\section{EXPERIMENTAL PROCEDURE}

\section{Materials and general methods}

2,1,3-Benzoxadiazole-4,7-bis(boronic acid pinacol ester), 2,5-dibromothiophene, 5,5'-dibromo-2,2'-bithiophene, 2,5-bis(trimethylstannyl)thiophene, 5,5'-bis (trimethylstannyl)-2,2'-bithiophene, $\mathrm{Pd}(\mathrm{OAc})_{2}, \mathrm{Pd}\left(\mathrm{PPh}_{3}\right)_{4}$ and pivalic acid $(\mathrm{PivOH})$ were purchased from Sigma-Aldrich and used without further purification. 4,7-Dibromo-2,1,3-BT and 3-dibromo-5-hexyl-5H-thienopyrrole4,6-dione ${ }^{42}$ were synthesized by modification of established procedures. Compounds 4,4-bis(2-ethylhexyl)-4H-cyclopenta[2,1- $\left.b ; 3,4-b^{\prime}\right]$ dithiophene, M1, P1, P1-DA and P3 were synthesized according to our previous report. ${ }^{12,62,63}$ Synthesis was performed under nitrogen atmosphere using standard Schlenk techniques. Compounds were purified by preparative size exclusion chromatography (SEC) using JAI LC-9204 with a column GAIGEL-1H-40 eluted with chloroform (flow rate $=14 \mathrm{ml} \mathrm{min}^{-1}$ ). Polymer molecular weight was determined by GPC in THF solution using a JASCO 880-PU and a JASCO 870-UV detector (JASCO, Tokyo, Japan, referenced to polystyrene standards). ${ }^{1} \mathrm{H}$ nuclear magnetic resonance (NMR) spectra were obtained using a Bruker $500 \mathrm{MHz}$ spectrometer (Bruker, Karlsruhe, Germany). Ultraviolet-visible absorption spectra were recorded on a Hitachi U-3300 ultraviolet-visible spectrophotometer (Hitachi high-technology Global, Tokyo, Japan). Cyclic voltammetry was performed at $0.10 \mathrm{~V} \mathrm{~s}^{-1}$ in a DY2300 electrochemical analyzer (BAS Inc., Tokyo, Japan) with a three-electrode cell, $\mathrm{AgCl} / \mathrm{Ag}$ as reference electrode, platinum wire as counter electrode and polymer film on a platinum plate as the working electrode in nitrogen-purged anhydrous $0.10 \mathrm{M}$ tetrabutylammonium hexafluorophosphate acetonitrile solution at room temperature.

\section{Synthesis of M3}

M1 $(0.410 \mathrm{~g}, 0.438 \mathrm{mmol})$ was dissolved in $4.0 \mathrm{ml}$ of THF. $\mathrm{N}$-bromosuccinimide (NBS; $0.172 \mathrm{~g}, 0.966 \mathrm{mmol}$ ) was dissolved in $5.0 \mathrm{ml}$ of THF and added dropwise at $0{ }^{\circ} \mathrm{C}$. The resulting solution was stirred for an hour. After THF was removed under vacuum, the product was dissolved in hexane and purified by column chromatography on silica gel using hexane as an eluent. Furthermore, the product was purified by preparative SEC using chloroform as an eluent. The product was obtained as dark purple oil ( $0.347 \mathrm{~g}, 72 \%$ yield). ${ }^{1} \mathrm{H}$ NMR $\left(500 \mathrm{MHz}, \mathrm{CDCl}_{3}\right): \delta 8.03,8.01,7.99(\mathrm{~s}, 2 \mathrm{H}, 3$-CPDT, the ratio was 1:2:1 due to racemic 2-ethylhexyl groups), 7.79 (s, 2H, BT), 6.98, 6.97, 6.96 (s, 2H, 5-CPDT, the ratio was 1:2:1 due to racemic 2-ethylhexyl groups), 1.99-1.83 
(m, 8H, $\left.\mathrm{CH}_{2}\right), 1.24(\mathrm{~m}, 4 \mathrm{H}, \mathrm{CH}), 1.03-0.59\left(\mathrm{~m}, 32 \mathrm{H}, \mathrm{CH}_{2}, \mathrm{CH}_{3}\right) .{ }^{13} \mathrm{C} \mathrm{NMR}$ $\left(125 \mathrm{MHz}, \mathrm{CDCl}_{3}\right): \delta 157.8,157.0,152.5,139.5,138.1,137.3,126.0,125.4$ $(\mathrm{CH}), 124.2(\mathrm{CH}), 122.5(\mathrm{CH}), 54.6(4-\mathrm{CPDT}), 43.1\left(\mathrm{CH}_{2}\right), 35.2(\mathrm{CH}), 34.1$, 28.5, 27.4 and $22.8\left(\mathrm{CH}_{2}\right), 14.0$ and $10.7\left(\mathrm{CH}_{3}\right)$. Fast atom bombardment mass spectroscopy (FABMS): $m / z=1095[\mathrm{M}]^{+}$.

\section{Synthesis of M2}

4,4-bis(2-ethylhexyl)-4H-cyclopenta[2,1-b;3,4- $\left.b^{\prime}\right]$ dithiophene (1.63 g, $4.06 \mathrm{mmol}$ ), 1,3-dibromo-5-hexyl-5H-thienopyrrole-4,6-dione $\quad(0.200 \mathrm{~g}, \quad 0.508 \mathrm{mmol})$, $\mathrm{K}_{2} \mathrm{CO}_{3}(0.352 \mathrm{~g}, 1.27 \mathrm{mmol}), \mathrm{Pd}(\mathrm{OAc})_{2}(56 \mathrm{mg}, 0.25 \mathrm{mmol})$ and $\mathrm{PivOH}$ ( $76 \mathrm{mg}, 0.75 \mathrm{mmol}$ ) were dissolved in $45 \mathrm{ml}$ of DMF in a $250 \mathrm{ml}$ Schlenk tube. The solution was purged with nitrogen gas for $5 \mathrm{~min}$. After the reaction mixture was stirred at $80^{\circ} \mathrm{C}$ for $2 \mathrm{~h}$, the organic layer was directly dried in vacuo to remove DMF. The reaction residue was purified by column chromatography on silica gel using a mixture of hexane and dichloromethane (1:1) as an eluent. This was then concentrated in vacuo and dissolved in $10 \mathrm{ml}$ of chloroform to use preparative SEC (flow rate $=14 \mathrm{ml} \mathrm{min}^{-1}$ ) to give a yellow orange oil (228 mg, 43\%). ${ }^{1} \mathrm{H}$ NMR $\left(500 \mathrm{MHz}, \mathrm{CDCl}_{3}\right): \delta 7.95,7.91,7.88(\mathrm{~s}, 2 \mathrm{H}$, 3-CPDT, the ratio was 1:2:1 due to racemic 2-ethylhexyl groups), 7.25 (d, J=5.0 Hz, 2H, 6-CPDT), $6.97(\mathrm{~m}, 2 \mathrm{H}, 5$-CPDT), $3.69(\mathrm{t}, 2 \mathrm{H}$, $J=10.0 \mathrm{~Hz}, \alpha$ proton of TPD), 2.17-0.61 (m, 49H, CH, $\mathrm{CH}_{2}$ and $\left.\mathrm{CH}_{3}\right)$. FABMS: $m / z=1038[\mathrm{M}]^{+}$

\section{Synthesis of M4}

M2 $(0.428 \mathrm{~g}, 0.412 \mathrm{mmol})$ was dissolved in $10 \mathrm{ml}$ of THF. NBS $(0.161 \mathrm{~g}$, $0.906 \mathrm{mmol}$ ) was dissolved in $10 \mathrm{ml}$ of THF and added dropwise at $0{ }^{\circ} \mathrm{C}$. The resulting solution was stirred for an hour. After THF was removed under vacuum, the product was dissolved in dichloromethane and purified by column chromatography on silica gel using a mixture of hexane and dichloromethane (1:1) as an eluent. Furthermore, the product was purified by preparative SEC using chloroform as an eluent. The product was obtained as light yellow oil (0.416 g, 84\% yield). ${ }^{1} \mathrm{H}$ NMR (500 MHz, $\left.\mathrm{CDCl}_{3}\right): \delta 7.89,7.86,7.82(\mathrm{~s}, 2 \mathrm{H}$, 3-CPDT, the ratio was 1:2:1 due to racemic 2-ethylhexyl groups), 6.98, 6.97, 6.96 (s, 2H, 5-CPDT, the ratio was 1:2:1 due to racemic 2-ethylhexyl groups), $3.66\left(\mathrm{t}, 2 \mathrm{H}, J=7.5 \mathrm{~Hz}, \alpha\right.$ proton of TPD), $1.94-0.58\left(\mathrm{~m}, 49 \mathrm{H}, \mathrm{CH}, \mathrm{CH}_{2}\right.$ and $\left.\mathrm{CH}_{3}\right) .{ }^{13} \mathrm{C}$ NMR $\left(125 \mathrm{MHz}, \mathrm{CDCl}_{3}\right): \delta 162.7,158.3,157.8,140.5,136.4,132.2$, 127.3, 125.4 (5-CPDT), 124.4 (3-CPDT), 113.1, 54.7 (4-CPDT), 43.0 and 38.6 $\left(\mathrm{CH}_{2}\right), 35.2(\mathrm{CH}), 34.1,31.4,28.6,28.4,27.4,26.6,22.8$ and $22.5\left(\mathrm{CH}_{2}\right), 14.1$, 14.0 and $10.7\left(\mathrm{CH}_{3}\right)$. FABMS: $m / z=1196[\mathrm{M}]^{+}$.

\section{Synthesis of P2 by Suzuki coupling}

M4 (98 mg, $0.082 \mathrm{mmol}$ ) and 2,1,3-BT-4,7-bis(boronic acid pinacol ester) (33 mg, $0.086 \mathrm{mmol}), \mathrm{K}_{2} \mathrm{CO}_{3}$ aqueous solution $(0.5 \mathrm{ml}, 2 \mathrm{M})$ and 1 drop of Aliquat 336 (Sigma-Aldrich China Inc., Shanghai, China) were dissolved in $1.6 \mathrm{ml}$ xylenes in a $25 \mathrm{ml}$ Schlenk tube. The solution was purged with an argon for $30 \mathrm{~min}$, then tetrakis(triphenylphosphine)palladium $(0) \quad(4.74 \mathrm{mg}$, $0.004 \mathrm{mmol}$ ) was added. The reaction was stirred at $90^{\circ} \mathrm{C}$ for 1 day and then benzeneboronic acid 2,2-dimethyltrimethylene ester (0.1 equiv.) was added followed by the addition of 4-bromoanisole ( 0.2 equiv.), stirring for another $8 \mathrm{~h}$. After that the resulting mixture was poured into $150 \mathrm{ml}$ methanol with $8 \mathrm{ml} 37 \mathrm{wt} \%$ hydrochloric acid. The precipitate was washed by Soxhlet extraction with ethanol and methylethylketone for a day and then extracted into chloroform. The chloroform solution of the polymer was filtered through a flash column of silica gel and then precipitated into methanol. The precipitate was collected using centrifugation at 6000 r.p.m. for $1 \mathrm{~min}$ and the solid was dried in vacuum to yield a dark blue powder (67 mg, 70\% yield). ${ }^{1} \mathrm{H}$ NMR $\left(500 \mathrm{MHz}, \mathrm{CDCl}_{3}\right): \delta 8.11$ (br, $2 \mathrm{H}$, thienyl), 7.97 (br, 2H, thienyl), 7.87 (br, $2 \mathrm{H}$, phenyl), 3.70 (br, $2 \mathrm{H}, \mathrm{CH}_{2}$ ), 2.02-0.50 (br, $79 \mathrm{H}, \mathrm{CH}, \mathrm{CH}_{2}$ and $\mathrm{CH}_{3}$ ). GPC (THF, polystyrene standard): average molecular weight $\left(M_{\mathrm{n}}\right)=14100$, $M_{\mathrm{w}} / M_{\mathrm{n}}=2.04$.

\section{Synthesis of P2-DA by direct arylation}

M2 $(80 \mathrm{mg}, \quad 0.077 \mathrm{mmol}), \quad 4,7$-dibromobenzo-1,2,5-thiadiazole $(23 \mathrm{mg}$, $0.077 \mathrm{mmol}), \mathrm{K}_{2} \mathrm{CO}_{3}(27 \mathrm{mg}, 0.193 \mathrm{mmol}), \mathrm{Pd}(\mathrm{OAc})_{2}(0.9 \mathrm{mg}, 0.004 \mathrm{mmol}$, $10 \mathrm{~mol} \%)$ and $\mathrm{PivOH}(2.4 \mathrm{mg}, 0.023 \mathrm{mmol}$ ) were dissolved in $1.2 \mathrm{ml}$ of $\mathrm{N}$ methylpyrrolidone (NMP) in a $10 \mathrm{ml}$ Schlenk tube. The solution was purged with nitrogen gas for $5 \mathrm{~min}$, then the mixture was stirred at $80{ }^{\circ} \mathrm{C}$ for $20 \mathrm{~h}$. After that the resulting mixture was poured into $100 \mathrm{ml}$ methanol with $6 \mathrm{ml} 37$ $\mathrm{wt} \%$ hydrochloric acid, the precipitate was washed by Soxhlet extraction with ethanol and methylethylketone for a day and then extracted into chloroform. The chloroform solution of the polymer was filtered through a flash column of silica gel and then precipitated into methanol. The precipitate was collected using centrifugation at 6000 r.p.m. for $1 \mathrm{~min}$ and the solid dried in vacuum to yield a dark blue powder (41 mg, 46\% yield). $\delta 8.11$ (br, $2 \mathrm{H}$, thienyl), 7.97 (br, $2 \mathrm{H}$, thienyl), 7.87 (br, $2 \mathrm{H}$, phenyl), 3.70 (br, $2 \mathrm{H}, \mathrm{CH}_{2}$ ), 2.02-0.50 (br, $79 \mathrm{H}$, $\mathrm{CH}, \mathrm{CH}_{2}$ and $\mathrm{CH}_{3}$ ). GPC (THF, polystyrene standard): $M_{\mathrm{n}}=8500$, $M_{\mathrm{w}} / M_{\mathrm{n}}=1.54$.

\section{Synthesis of P4 oxidative polymerization}

Anhydrous $\mathrm{FeCl}_{3}(38 \mathrm{mg}, 0.24 \mathrm{mmol}$ ) was slowly added to a solution of $\mathbf{M} 2$ (100 mg, $0.096 \mathrm{mmol}$ ) in $2.5 \mathrm{ml}$ of anhydrous chlorobenzene under nitrogen gas atmosphere. The reaction mixture was stirred at $80^{\circ} \mathrm{C}$ for 3 days. After the polymerization, the reaction mixture was precipitated into methanol containing $5 \%$ hydrazine hydrate. The precipitate was washed by Soxhlet extraction with ethanol and methylethylketone for a day and then extracted into chloroform. The chloroform solution of the polymer was filtered through a flash column of silica gel and then precipitated into methanol. The precipitate was collected using centrifugation at 6000 r.p.m. for $1 \mathrm{~min}$ and the solid dried in vacuum to yield a deep blue powder $\left(60 \mathrm{mg}, 60 \%\right.$ yield). ${ }^{1} \mathrm{H}$ NMR $\left(500 \mathrm{MHz}, \mathrm{CDCl}_{3}\right)$ : $\delta 7.88$ (br, $2 \mathrm{H}$, thienyl), 7.05 (br, $2 \mathrm{H}$, thienyl), 3.68-3.47 (br, $2 \mathrm{H}, \mathrm{CH}_{2}$ ), 1.94-0.65 (br, 79H, $\mathrm{CH}, \mathrm{CH}_{2}$ and $\mathrm{CH}_{3}$ ). GPC (THF, polystyrene standard): $M_{\mathrm{n}}=52900, M_{\mathrm{w}} / M_{\mathrm{n}}=2.38$.

\section{Synthesis of P5 by Stille coupling}

M3 (130 mg, $0.119 \mathrm{mmol}$ ) and 2,5-bis(trimethylstannyl)thiophene (49 mg, $0.119 \mathrm{mmol}$ ) were dissolved in $1.8 \mathrm{ml}$ anhydrous $p$-xylene and $0.6 \mathrm{ml}$ anhydrous DMF in a $10 \mathrm{ml}$ Schlenk tube. The solution was purged with an argon for $30 \mathrm{~min}$, then tetrakis(triphenylphosphine)palladium(0) $(6.9 \mathrm{mg}$, $0.006 \mathrm{mmol}$ ) was added. The reaction mixture was stirred at $120^{\circ} \mathrm{C}$ for 1 day. After that the resulting mixture was poured into $150 \mathrm{ml}$ methanol with $8 \mathrm{ml} 37 \mathrm{wt} \%$ hydrochloric acid. The precipitate was washed by Soxhlet extraction with ethanol and methylethylketone for a day and then extracted into chloroform. The chloroform solution of the polymer was filtered through a flash column of silica gel and then precipitated into methanol. The precipitate was collected using centrifugation at 6000 r.p.m. for $1 \mathrm{~min}$ and the solid was dried in vacuum to yield a dark blue powder ( $98 \mathrm{mg}, 81 \%$ yield). ${ }^{1} \mathrm{H}$ NMR $\left(500 \mathrm{MHz}, \mathrm{CDCl}_{3}\right): \delta 8.06$ (br, 2H, 3-CPDT), 7.81 (br, $2 \mathrm{H}$, phenyl), 7.07 (br, 3H, 5-CPDT and thiophene), 1.97 (br, 8H, $\left.\mathrm{CH}_{2}\right), 1.18-0.45(\mathrm{~m}, 30 \mathrm{H}, \mathrm{CH}$, $\mathrm{CH}_{2}$ and $\mathrm{CH}_{3}$ ). GPC (THF, polystyrene standard): $M_{\mathrm{n}}=17900, M_{\mathrm{w}} / M_{\mathrm{n}}=1.71$.

\section{Synthesis of P5-DA by direct arylation}

P5-DA was synthesized by similar procedure to P2-DA using M1 (139 mg, $0.149 \mathrm{mmol}), 2,5$-dibromothiophene $(36.1 \mathrm{mg}, 0.149 \mathrm{mmol}), \mathrm{K}_{2} \mathrm{CO}_{3}(515 \mathrm{mg}$, $0.373 \mathrm{mmol}), \mathrm{Pd}(\mathrm{OAc})_{2}(3.5 \mathrm{mg}, 0.016 \mathrm{mmol}, 10 \mathrm{~mol} \%), \mathrm{PivOH}(4.6 \mathrm{mg}$, $0.045 \mathrm{mmol})$ and $1.6 \mathrm{ml} \mathrm{NMP}$ to yield a dark blue powder $(80 \mathrm{mg}, 53 \%$ yield). ${ }^{1} \mathrm{H}$ NMR (500 MHz, $\mathrm{CDCl}_{3}$ ): $\delta 8.05$ (br, 2H, 3-CPDT), 7.81 (br, 2H, phenyl), 7.07 (br, 3H, 5-CPDT and thiophene), $1.98\left(\mathrm{br}, 8 \mathrm{H}, \mathrm{CH}_{2}\right), 1.10-0.58(\mathrm{~m}, 30 \mathrm{H}$, $\mathrm{CH}, \mathrm{CH}_{2}$ and $\mathrm{CH}_{3}$ ). GPC (THF, polystyrene standard): $M_{\mathrm{n}}=27600$, $M_{\mathrm{w}} / M_{\mathrm{n}}=1.88$.

\section{Synthesis of P6 by Stille coupling}

P6 was synthesized by similar procedure to P5 using M4 (97 mg, $0.081 \mathrm{mmol}$ ), 2,5-bis(trimethylstannyl)thiophene (33 mg, $0.081 \mathrm{mmol}$ ), $1.2 \mathrm{ml}$ anhydrous p-xylene, $0.4 \mathrm{ml}$ anhydrous DMF and tetrakis(triphenylphosphine)palladium (0) $(4.7 \mathrm{mg}, 0.004 \mathrm{mmol})$ to yield a dark purple powder (64 mg, $71 \%$ yield). ${ }^{1} \mathrm{H}$ NMR (500 MHz, $\left.\mathrm{CDCl}_{3}\right): \delta 7.90$ (br, $2 \mathrm{H}$, thienyl), 7.10 (br, $2 \mathrm{H}$, thiophene), 7.06 (br, $2 \mathrm{H}$, thienyl), 3.68 (br, $2 \mathrm{H}, \mathrm{CH}_{2}$ ), 1.94-0.65 (br, 79H, $\mathrm{CH}, \mathrm{CH}_{2}$ and $\mathrm{CH}_{3}$ ). GPC (THF, polystyrene standard): $M_{\mathrm{n}}=50500, M_{\mathrm{w}} / M_{\mathrm{n}}=3.05$. 
Monomer synthesis

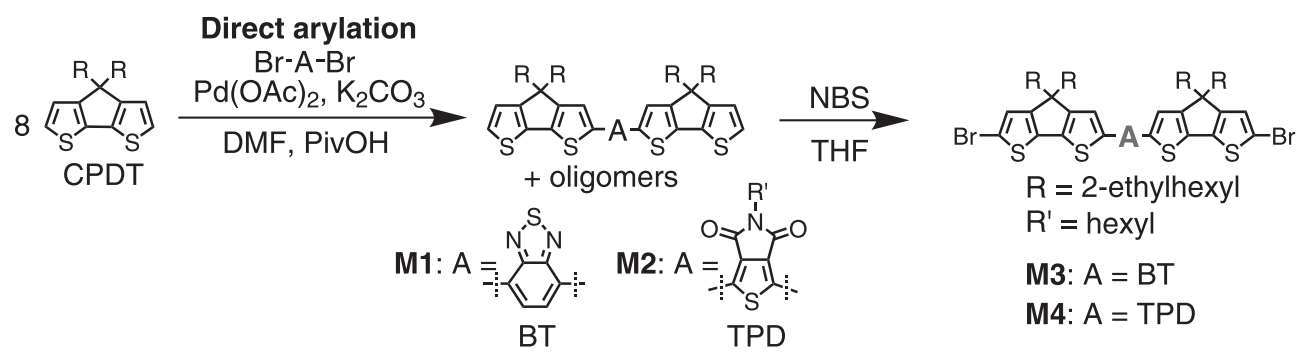

Polymer synthesis

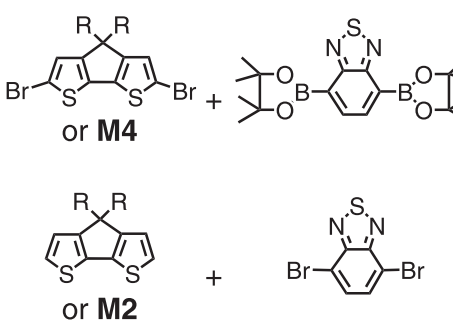

M1 or M2

Suzuki coupling
$\mathrm{Pd}\left(\mathrm{PPh}_{3}\right)_{4}, \mathrm{~K}_{2} \mathrm{CO}_{3}$
xylene $/ \mathrm{H}_{2} \mathrm{O}$

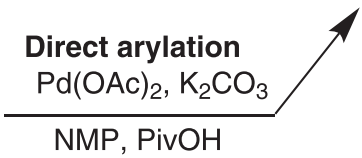

Oxidative polymerization

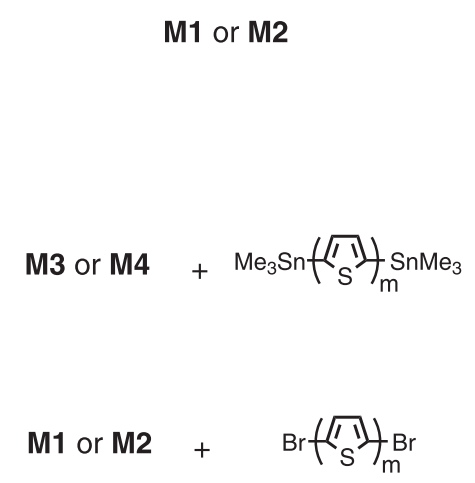

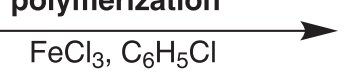

Stille coupling $\mathrm{Pd}\left(\mathrm{PPh}_{3}\right)_{4}$

xylene

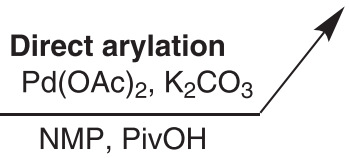

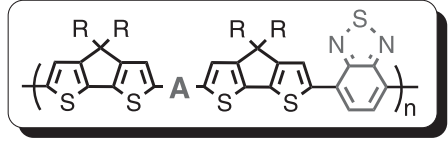

P1 \& P1-DA: $A=B T$

P2 \& P2-DA: A = TPD

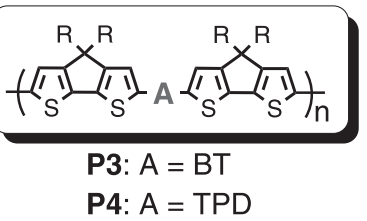

P4: $A=$ TPD

Scheme 1 Synthesis of monomers and polymers. A full color version of this scheme is available at Polymer Journal online.

Synthesis of P6-DA by direct arylation

P6-DA was synthesized by similar procedure to P2-DA using M2 (100 mg, $0.096 \mathrm{mmol}), 2,5$-dibromothiophene $(23 \mathrm{mg}, 0.096 \mathrm{mmol}), \mathrm{K}_{2} \mathrm{CO}_{3}(33 \mathrm{mg}$, $0.240 \mathrm{mmol}), \mathrm{Pd}(\mathrm{OAc})_{2}(2.2 \mathrm{mg}, 0.010 \mathrm{mmol}, 10 \mathrm{~mol} \%)$, PivOH $(3.0 \mathrm{mg}$, $0.029 \mathrm{mmol}$ ) and $1.5 \mathrm{ml} \mathrm{NMP}$ to yield a dark blue powder $(23 \mathrm{mg}, 21 \%$ yield). ${ }^{1} \mathrm{H}$ NMR $\left(500 \mathrm{MHz}, \mathrm{CDCl}_{3}\right.$ ): $\delta 7.90$ (br, $2 \mathrm{H}$, thienyl), 7.10 (br, $2 \mathrm{H}$, thiophene), 7.06 (br, $2 \mathrm{H}$, thienyl), 3.68 (br, $2 \mathrm{H}, \mathrm{CH}_{2}$ ), $1.94-0.65$ (br, $79 \mathrm{H}, \mathrm{CH}, \mathrm{CH}_{2}$ and $\mathrm{CH}_{3}$ ). GPC (THF, polystyrene standard): $M_{\mathrm{n}}=5200, M_{\mathrm{w}} / M_{\mathrm{n}}=1.64$.

\section{Synthesis of P7 by Stille coupling}

P7 was synthesized by similar procedure to P5 using M3 (91 mg, $0.076 \mathrm{mmol}$ ), 5,5'-bis(trimethylstannyl)-2,2'-bithiophene $\quad(38 \mathrm{mg}, \quad 0.078 \mathrm{mmol}), \quad 1.1 \mathrm{ml}$ anhydrous $p$-xylene, $0.4 \mathrm{ml}$ anhydrous DMF and tetrakis(triphenylphosphine) palladium(0) (4.4 mg, $0.006 \mathrm{mmol})$ to yield a dark blue powder $(60 \mathrm{mg}, 66 \%$ yield). ${ }^{1} \mathrm{H}$ NMR $\left(500 \mathrm{MHz}, \mathrm{CDCl}_{3}\right.$ ): $\delta 7.90$ (br, $2 \mathrm{H}$, thienyl), 7.09 (br, $4 \mathrm{H}$, thiophene), 7.06 (br, $2 \mathrm{H}$, thienyl), 3.67 (br, $2 \mathrm{H}, \mathrm{CH}_{2}$ ), 1.94-0.65 (br, $79 \mathrm{H}, \mathrm{CH}$, $\mathrm{CH}_{2}$ and $\mathrm{CH}_{3}$ ). GPC (THF, polystyrene standard): $M_{\mathrm{n}}=23400, M_{\mathrm{w}} / M_{\mathrm{n}}=1.75$.

\section{Synthesis of P7-DA by direct arylation}

P7-DA was synthesized by similar procedure to P2-DA using M2 (100 mg, $0.096 \mathrm{mmol}$ ), 5,5'-dibromo-2,2'-bithiophene (31 mg, $0.096 \mathrm{mmol}), \mathrm{K}_{2} \mathrm{CO}_{3}$ (33 mg, $0.24 \mathrm{mmol}), \mathrm{Pd}(\mathrm{OAc})_{2}(2.2 \mathrm{mg}, 0.010 \mathrm{mmol}, 10 \mathrm{~mol} \%), \mathrm{PivOH}$ $(3.0 \mathrm{mg}, 0.029 \mathrm{mmol}$ ) and $1.5 \mathrm{ml} \mathrm{NMP}$ to yield a dark blue powder $(30 \mathrm{mg}$, $26 \%$ yield). ${ }^{1} \mathrm{H}$ NMR $\left(500 \mathrm{MHz}, \mathrm{CDCl}_{3}\right.$ ): $\delta 7.90$ (br, $2 \mathrm{H}$, thienyl), 7.09 (br, $4 \mathrm{H}$, thiophene), 7.06 (br, 2H, thienyl), 3.67 (br, $2 \mathrm{H}, \mathrm{CH}_{2}$ ), 1.94-0.65 (br, 79H, CH, $\mathrm{CH}_{2}$ and $\mathrm{CH}_{3}$ ). GPC (THF, polystyrene standard): $M_{\mathrm{n}}=11400, M_{\mathrm{w}} / M_{\mathrm{n}}=1.96$.

Synthesis of P8 by Stille coupling

P8 was synthesized by similar procedure to P5 using M4 (130 mg, $0.119 \mathrm{mmol}$ ), 5,5'-bis(trimethylstannyl)-2,2'-bithiophene (58 mg, $0.119 \mathrm{mmol}$ ), $1.8 \mathrm{ml}$ anhydrous p-xylene, $0.6 \mathrm{ml}$ anhydrous DMF and tetrakis(triphenylphosphine)palladium $(0)(6.9 \mathrm{mg}, 0.006 \mathrm{mmol})$ to yield a dark blue powder (110 mg, 84\% yield). ${ }^{1} \mathrm{H}$ NMR (500 MHz, $\mathrm{CDCl}_{3}$ ): $\delta 8.05$ (br, 2H, 3-CPDT), 7.81 (br, 2H, phenyl), 7.07 (br, 6H, 5-CPDT and bithiophene), 1.97 (br, $8 \mathrm{H}$, $\left.\mathrm{CH}_{2}\right), 1.10-0.60\left(\mathrm{~m}, 30 \mathrm{H}, \mathrm{CH}, \mathrm{CH}_{2}\right.$ and $\mathrm{CH}_{3}$ ). GPC (THF, polystyrene standard): $M_{\mathrm{n}}=27600, M_{\mathrm{w}} / M_{\mathrm{n}}=1.88$.

Synthesis of P8-DA by direct arylation

P8-DA was synthesized by similar procedure to P2-DA using M4 (139 mg, $0.149 \mathrm{mmol}$ ), 5,5'-dibromo-2,2'-bithiophene (48 mg, $0.149 \mathrm{mmol}$ ), $\mathrm{K}_{2} \mathrm{CO}_{3}$ (515 mg, $0.373 \mathrm{mmol}), \mathrm{Pd}(\mathrm{OAc})_{2}$ ( $3.5 \mathrm{mg}, 0.016 \mathrm{mmol}, 10 \mathrm{~mol} \%$ ), PivOH (4.6 $\mathrm{mg}, 0.045 \mathrm{mmol}$ ) and $1.6 \mathrm{ml} \mathrm{NMP} \mathrm{to} \mathrm{yield} \mathrm{a} \mathrm{dark} \mathrm{blue} \mathrm{powder}(37 \mathrm{mg}$, $23 \%$ yield). ${ }^{1} \mathrm{H}$ NMR $\left(500 \mathrm{MHz}, \mathrm{CDCl}_{3}\right.$ ): $\delta 8.05$ (br, 2H, 3-CPDT), 7.81 (br, $2 \mathrm{H}$, phenyl), 7.07 (br, 6H, 5-CPDT and bithiophene), 1.97 (br, $8 \mathrm{H}, \mathrm{CH}_{2}$ ), 1.10-0.60 (m, $30 \mathrm{H}, \mathrm{CH}, \mathrm{CH}_{2}$ and $\mathrm{CH}_{3}$ ). GPC (THF, polystyrene standard): $M_{\mathrm{n}}=15600, M_{\mathrm{w}} / M_{\mathrm{n}}=1.76$. 


\section{Fabrication of OPV}

ITO substrates were prepared with a PEDOT:PSS layer, prior to coating the active layer. Prior to coating, the polymer:phenyl- $\mathrm{C}_{71}$-butyric acid methyl ester $\left(\mathrm{PC}_{71} \mathrm{BM}\right)$ blends were allowed to dissolve for $20 \mathrm{~h}$ on a hot plate stirrer and filtered using a $0.45 \mu \mathrm{m}$ polytetrafluoroethene (PTFE) filter. The chlorobenzene solutions containing polymer, $\mathrm{PC}_{71} \mathrm{BM}$ and 1,8-octanedithiol (ODT) with a weight ratio of 1:3:3 were spun-cast using different spinning rates on to these PEDOT:PSS-coated substrates. The cathode electrodes consisted of $10 \mathrm{~nm}$ calcium followed by $100 \mathrm{~nm}$ aluminum. Current-voltage $(J-V)$ characteristics of these PV devices were measured under white light illumination (AM1.5) using a Wacom WXS-50S-1.5 solar simulator (Wacom, Saitama, Japan) output intensity of $100 \mathrm{~mW} \mathrm{~cm}^{-2}$.

\section{RESULTS AND DISCUSSION}

\section{Synthesis of materials}

Scheme 1 shows the monomer and polymer synthesis. Oligomers M1 and $\mathbf{M} 2$, comprising two CPDT units and one BT or TPD unit, were synthesized by the direct arylation of CPDT with dibrominated BT or TPD in the presence of $\mathrm{Pd}(\mathrm{OAc})_{2}, \mathrm{~K}_{2} \mathrm{CO}_{3}$ and $\mathrm{PivOH}$ in $\mathrm{DMF}$ at $80^{\circ} \mathrm{C}$ for $2 \mathrm{~h}$; these conditions are similar to those used in our previous reports. ${ }^{62,63}$ Direct arylation simplifies the reaction steps and processes because adding organometallic functional groups to CPDT is unnecessary. M2 was obtained in 43\% yield, which was comparable with M1 (45\%). These monomers were used for direct arylation polymerization or were further brominated using NBS to give M3 and M4, which were subsequently used in Stille or Suzuki coupling polymerizations. The chemical structures of the monomers were analyzed using ${ }^{1} \mathrm{H}$ and ${ }^{13} \mathrm{C}$ NMR spectroscopy and FABMS (see Experimental section and Supplementary Figures $\mathrm{S} 1-\mathrm{S} 13$ in Supplementary Information).

Table 1 shows the results of the polymerization reactions. P1 and P2, with D-A ratios of $1: 1$ in the backbone, were synthesized by Suzuki coupling polymerization. P1, also known as PCPDT-BT, was obtained by coupling dibromo-CPDT with 2,1,3-BT-4,7-bis(boronic acid pinacol ester) using an ultra-low loading of a palladium catalyst (5.9 p.p.m.) at an optimal temperature of $110^{\circ} \mathrm{C}$ and showed a high number $M_{\mathrm{n}}$ of $53200 .{ }^{64}$ The double acceptor copolymer P2 was obtained by the coupling of M4 with 2,1,3-BT-4,7-bis(boronic acid pinacol ester) using $5 \mathrm{~mol} \%$ of $\mathrm{Pd}\left(\mathrm{PPh}_{3}\right)_{4}$ and showed $M_{\mathrm{n}}=14100$.

Table 1 Polymer molecular weights and reaction yields

\begin{tabular}{lllccc}
\hline Polymer & \multicolumn{1}{c}{ group } & \multicolumn{1}{c}{ Protocol } & $M_{n}{ }^{\mathrm{a}}$ & $M_{w} / M_{n}{ }^{\mathrm{a}}$ & Yield (\%) \\
\hline P1 & BT/BT & Suzuki coupling & 53200 & 3.7 & 88 \\
P1-DA & BT/BT & Direct arylation & 71700 & 4.5 & 76 \\
P2 & TPD/BT & Suzuki coupling & 14100 & 2.0 & 70 \\
P2-DA & TPD/BT & Direct arylation & 8600 & 1.5 & 46 \\
P3 & BT/none & FeCl $_{3}$ & 51300 & 3.7 & 76 \\
P4 & TPD/none & FeCl $_{3}$ & 52900 & 2.4 & 50 \\
P5 & BT/thiophene & Stille coupling & 17900 & 1.7 & 81 \\
P5-DA & BT/thiophene & Direct arylation & 15600 & 1.8 & 53 \\
P6 & TPD/thiophene & Stille coupling & 50500 & 3.1 & 71 \\
P6-DA & TPD/thiophene & Direct arylation & 5100 & 1.7 & 21 \\
P7 & BT/bithiophene & Stille coupling & 27600 & 1.9 & 84 \\
P7-DA & BT/bithiophene & Direct arylation & 15600 & 1.8 & 23 \\
P8 & TPD/bithiophene & Stille coupling & 23400 & 1.8 & 66 \\
P8-DA & TPD/bithiophene & Direct arylation & 11400 & 2.0 & 26 \\
\hline
\end{tabular}

a Calculated from gel permeation chromatography (GPC) measurements carried out using THF as the solvent and calibrated by polystyrene standards. Number-average molecular weight, $M_{\mathrm{n}}$ and polydispersity index after Soxhlet extraction.

bYield after Soxhlet extraction.
P3 and P4, comprising two CPDT units and one BT or TPD unit, respectively, were synthesized from $\mathbf{M 1}$ and $\mathbf{M} 2$, respectively, by oxidative polymerization using $\mathrm{FeCl}_{3}$ in chlorobenzene; both $\mathbf{P} 3$ and P4 showed relatively high $M_{\mathrm{n}}$ values of 51300 and 52 900, respectively, compared with other copolymers obtained using cross-coupling reactions. Although P3 had a lower molecular weight than that reported in a previous study $\left(M_{\mathrm{n}}=107000\right),{ }^{12}$ the material prepared here possesses improved solubility, which is beneficial for solution-process device fabrication, thereby providing potentially higher OPV efficiency.

P5-P8, comprising thiophene or bithiophene units, were synthesized by Stille coupling polymerization between M3 or M4 and bis (trimethylstannyl)thiophene or bis(trimethylstannyl)bithiophene; the polymers showed $M_{\mathrm{n}}$ values of $17900,50500,27600$ and 23400 . Two reasons account for the high $M_{\mathrm{n}}$ value of P6. First, the TPD unit offers better solubility than the BT unit (P5 and P7) because of the presence of an additional alkyl side chain. Second, the thiophene unit in P6 improves the solubility of the polymer compared with P7 and P8 containing bithiophene generally reduces the solubility of polymers.

To compare the polymers obtained using the different synthetic methods, P1-DA, P2-DA and P5-DA-P8-DA, which have chemical structures identical to $\mathbf{P 1}, \mathbf{P} 2$ and $\mathbf{P 5 - P 8}$, were synthesized by direct arylation polymerization reactions between $\mathbf{M} 1$ or $\mathbf{M} 2$ and dibromo-BT, dibromothiophene or dibromobithiophene in the presence of $\mathrm{Pd}(\mathrm{OAc})_{2}, \mathrm{~K}_{2} \mathrm{CO}_{3}$ and $\mathrm{PivOH}$ in $\mathrm{NMP}$ at $80^{\circ} \mathrm{C}$ for $20 \mathrm{~h}$; these conditions are similar to the optimized conditions used for synthesizing $\mathbf{P} 1$ in our previous report. ${ }^{62}$

The copolymers synthesized by direct arylation showed lower $M_{\mathrm{n}}$ values than those prepared in cross-coupling reactions. This may be attributed to the lower reactivity of $\mathbf{M} 1$ and $\mathbf{M} 2$ compared with CPDT resulting from the presence of electron-deficient BT or TPD units. Kuwabara et al. ${ }^{39}$ reported that electron-deficient monomers were unreactive in palladium-catalyzed direct arylation reactions carried out in polar solvents such as $N, N$-dimethylacetamide. To overcome this, approaches such as increased reaction temperatures, longer reaction times or the addition of supporting ligands might be successful in improving the molecular weight, ${ }^{26,27,29,38,39,46,48,55,58}$ but the multiple reactive protons on CPDT easily lead to the formation of insoluble branched polymers under harsh reaction conditions. To completely exploit the merits of direct arylation, careful design and consideration of the monomer structure is necessary to avoid the occurrence of side reactions. In addition, CPDT-TPD-CPDT-based polymers prepared by direct arylation showed lower $M_{\mathrm{n}}$ values than their CPDT-BT-CPDT counterparts. It has been reported that monomers comprising carbonyl group are effective coupling partners in Stille coupling ${ }^{36,37,40-43}$ but less effective in direct arylation because of the presence of a base in the reaction mixture, which would affect the carbonyl groups on TPD. ${ }^{62,65}$ Despite the use of the less reactive TPD, the successful direct arylation employing CPDT-capped TPD (M2) provides an alternative route for synthesizing new materials under simpler and more mild reaction conditions than those described above.

The chemical structures of the newly prepared polymers were analyzed using ${ }^{1} \mathrm{H}$ NMR spectroscopy (Experimental section and Supplementary Figures S14-S18 in Supplementary Information). The polymers prepared using the Suzuki and Stille coupling methods showed ${ }^{1} \mathrm{H}$ NMR spectra consistent with the desired structures, whereas polymers prepared by direct arylation show additional minor signals resulting from side reactions, such as branching and CPDT-CPDT coupling. ${ }^{62,65}$ 


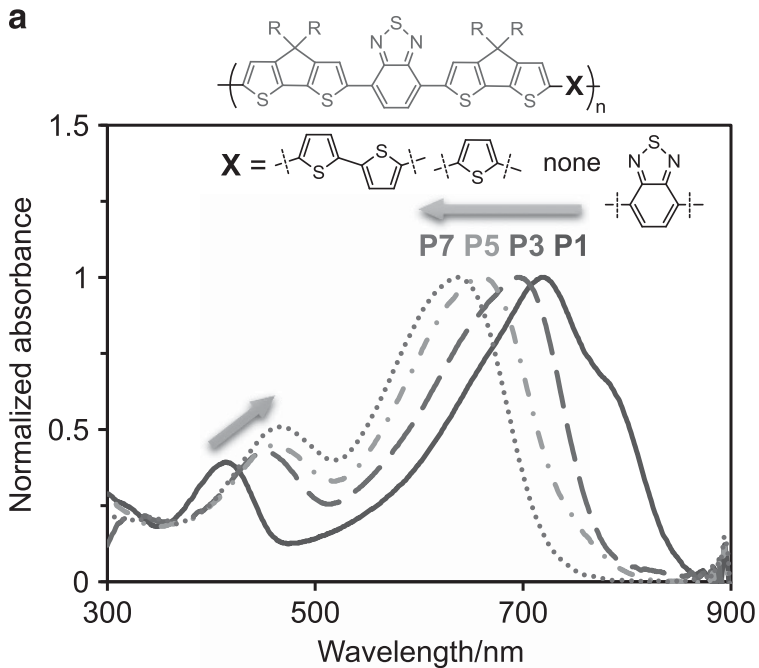

b

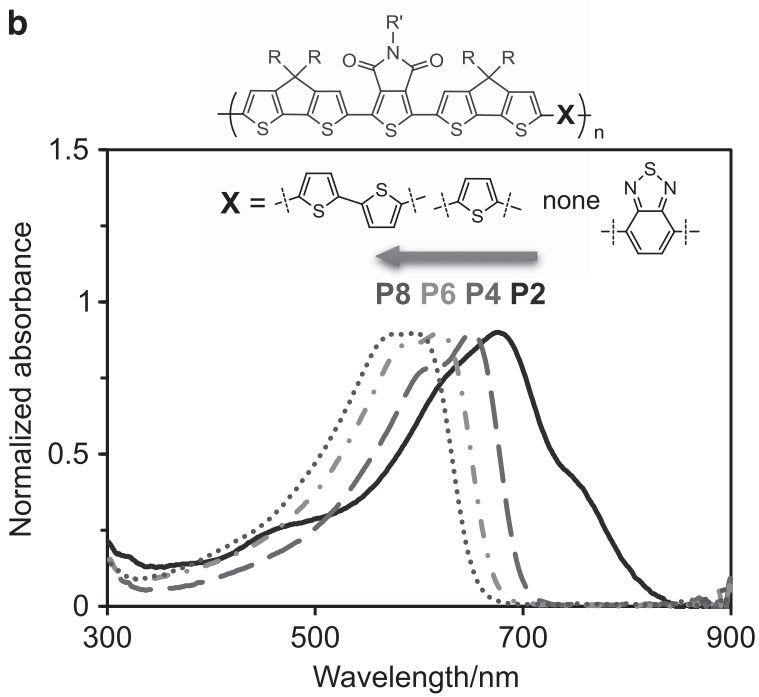

Figure 2 Ultraviolet-visible spectra of polymers P1-P8 in THF solution, (a) polymers $1,3,5,7$, (b) polymers $2,4,6,8$. THF, tetrahydrofuran. A full color version of this figure is available at Polymer Journal online.
Optical and electrochemical properties

Ultraviolet-visible absorption spectra. The ultraviolet-visible absorption spectra of P1-P8 were recorded in tetrahydrofuran (THF) solutions, and are shown in Figure 2. The optical band gaps $\left(E_{\text {g-opt }}\right)$ were estimated from the onset of the absorption spectra in thin films, and the results are summarized in Table 2. Copolymers of the CPDTBT-CPDT series show absorption maxima $\left(\lambda_{\max }\right)$ at $719 \mathrm{~nm}(\mathbf{P 1})$, $696 \mathrm{~nm}$ (P3), $662 \mathrm{~nm}$ (P5) and $638 \mathrm{~nm}$ (P7); this sequence corresponds to an increase in the relative amount of donor component present in the polymers. Moreover, this copolymer series shows an additional peak at lower wavelengths between 410 and $460 \mathrm{~nm}$. The wavelength position and peak intensity of the small peak increased with an increase in the relative number of electron donor units in the polymer, showing a tendency to merge the two peaks. This trend resembles the previous report. ${ }^{66}$ The CPDT-TPD-CPDT series also shows a similar trend, which is, a blueshift with an increase in the relative number of electron donor units, with $\lambda_{\max }=676 \mathrm{~nm}(\mathbf{P} 2)$, $650 \mathrm{~nm}$ (P4), $619 \mathrm{~nm}$ (P6) and $597 \mathrm{~nm}$ (P8).

By way of comparison between the two series, members of the CPDT-BT-CPDT series were redshifted by around $40 \mathrm{~nm}$ relative to the analogous members of the CPDT-TPD-CPDT series. This may be accounted for by more efficient quinoid formation between CPDT and BT than between CPDT and TPD. The short wavelength shifts within each series may be attributed to the weakened D-A interaction resulting from the insertion of thiophene(s); consequently the donor part dominates. Reynold and co-workers ${ }^{67}$ reported a similar series of copolymers using the fused ring donor dithieno[3,2-b:2', $\left.3^{\prime}-d\right]$ silole (DTS) in place of CPDT, but the order of $\lambda_{\max }$ was not in accordance with the increasing donor ratio in the backbone as is observed for the CPDT-BT-CPDT series. The DTS-BT-DTS series showed absorptions that were more blueshifted than members of the CPDT-BT-CPDT series that had the same connecting units because the smaller electronegativity of silicon compared with carbon $(\mathrm{Si}=1.9<\mathrm{C}=2.5)$ and the reduced $\pi$-electron bond-forming ability of the $\mathrm{Si}$ atom makes DTS a stronger donor than CPDT. Contradictorily, the DTS-BT-DTS copolymer connected with a bithiophene unit showed a longer $\lambda_{\max }$, at $617 \mathrm{~nm}$, than the copolymer connected with one thiophene unit $\left(\lambda_{\max }=602 \mathrm{~nm}\right)$; this is a specific phenomenon induced by DTS. ${ }^{67}$

Polymer films were prepared by drop casting chloroform solutions of the desired polymer onto glass substrates, and the $\lambda_{\max }$ values

Table 2 Optical and electrochemical properties of polymers

\begin{tabular}{|c|c|c|c|c|c|c|c|c|c|c|}
\hline \multirow[b]{2}{*}{ Polymer } & \multirow[b]{2}{*}{ Group } & \multicolumn{2}{|c|}{$\lambda_{\max }(n m)$} & \multirow[b]{2}{*}{$\Delta \lambda(n m)$} & \multirow[b]{2}{*}{$\mathrm{E}_{g \text {-opt }}(\mathrm{eV}) \mathrm{film}$} & \multicolumn{2}{|c|}{$\mathrm{E}_{1 / 2}$ vs $\mathrm{Ag} / \mathrm{AgCl}(\mathrm{V})$} & \multirow[b]{2}{*}{$H O M O^{\mathrm{b}}(\mathrm{eV})$} & \multirow[b]{2}{*}{$\angle U M O^{C}(\mathrm{eV})$} & \multirow[b]{2}{*}{$\mathrm{E}_{g-e c}{ }^{\mathrm{c}}(e \mathrm{~V})$} \\
\hline & & Solution & Film & & & $\mathrm{E}_{1 / 2}(\mathrm{Ox})$ & $\mathrm{E}_{1 / 2}(R d)$ & & & \\
\hline $\mathrm{P} 1$ & $\mathrm{BT} / \mathrm{BT}$ & 719 & 787 & 68 & 1.44 & 0.61 & 1.13 & -4.95 & -3.21 & 1.74 \\
\hline P2 & TPD/BT & 676 & 728 & 52 & 1.53 & 0.80 & 1.22 & -5.14 & -3.12 & 2.02 \\
\hline P3 & BT/none & 696 & 697 & 1 & 1.52 & 0.64 & 1.23 & -4.98 & -3.11 & 1.87 \\
\hline P4 & TPD/none & 650 & 683 & 33 & 1.68 & 0.82 & 1.37 & -5.16 & -2.97 & 2.19 \\
\hline P5 & BT/thiophene & 662 & 685 & 23 & 1.57 & 0.64 & 1.29 & -4.98 & -3.05 & 1.93 \\
\hline P6 & TPD/thiophene & 619 & 651 & 32 & 1.76 & 0.84 & 1.42 & -5.18 & -2.92 & 2.26 \\
\hline P7 & BT/bithiophene & 638 & 666 & 28 & 1.55 & 0.65 & 1.26 & -4.99 & -3.08 & 1.91 \\
\hline P8 & TPD/bithiophene & 597 & 635 & 38 & 1.78 & 0.85 & 1.48 & -5.19 & -2.86 & 2.33 \\
\hline
\end{tabular}

Abbreviations: $E_{\mathrm{g}-\mathrm{opt}}$, optical band gap; Ox, oxidation; Rd, reduction; $\Delta \lambda$, shift between film and solution.

Electrochemical band gap, $E_{\mathrm{g}-\mathrm{ec}}=\mathrm{LUMO}-\mathrm{HOMO}$.

${ }^{a} \mathrm{CV}$ of polymer films on Pt plate were measured in $\mathrm{MeCN}$ solution containing $0.10 \mathrm{~m} n-\mathrm{Bu}_{4} \mathrm{NPF}_{6}$.

${ }^{\mathrm{b}} \mathrm{HOMO}=-\left(4.8+E_{\mathrm{pa}-o n s e t}-E_{\mathrm{Fc}}\right)$. Half wave potential of ferrocene, $E_{\mathrm{Fc}}(=0.46 \mathrm{~V}$ vs $\mathrm{AgCl} / \mathrm{Ag})$, was measured in MeCN solution.

${ }^{\mathrm{C}} \mathrm{LUMO}=-\left(4.8+E_{\mathrm{pc}-o n s e t}-E_{\mathrm{Fc}}\right)$. 
recorded in the ultraviolet-visible spectra of the films were compared with those obtained in solution (Table 2 and Supplementary Figure S19 in Supplementary Information). The polymer films exhibited greater redshift than polymers in solution with an increase in the number of thiophene units. This is a result of the enhanced intermolecular $\pi-\pi$ stacking that occurs in the film state.

Overall, the insertion of thiophene(s) is an effective approach to achieve the desired sunlight absorption range and adjust the relative intensity of the two-band absorptions. This method is appropriate to design materials suitable for use in OPVs with wide absorption bands.

Energy levels. The electrochemical properties of P1-P8 were investigated by cyclic voltammetry, and HOMO/LUMO levels and electrochemical energy gaps $\left(E_{\mathrm{g}-\mathrm{ec}}\right)$ were estimated from the onset of CVs, as summarized in Table 2 and Figure 3. When comparing the CPDT-BT-CPDT and CPDT-TPD-CPDT series, it appears that the TPD unit more profoundly determines the HOMO level; the CPDT-TPD-CPDT series shows HOMO levels $\sim 0.2 \mathrm{eV}$ lower than those of the CPDT-BT-CPDT series, even in the presence of BT in P2. The HOMO levels of $\mathbf{P 2}, \mathbf{P 4}, \mathbf{P 6}$ and $\mathbf{P 8}$ were estimated to be in the range between -5.14 and $-5.19 \mathrm{eV}$, suggesting that the presence of the strongly electron-accepting TPD can reduce the energy of the HOMO. In addition, the CPDT-TPD-CPDT series showed LUMO levels $\sim 0.1-0.2 \mathrm{eV}$ higher in energy, leading to a higher electrochemical band gap than was observed in the CPDT-BT-CPDT series. These results indicate that the HOMO and LUMO energy levels are more strongly affected by the presence of the TPD unit in the polymer backbone than by the BT unit.

When comparing P1, P3, P5 and P7 in the CPDT-BT-CPDT series, a stepwise increase in the energy of the LUMO level was observed with an increase in the number of donor units; the energy of the HOMO level was unchanged. Similarly, when comparing P2, P4, P6 and P8 in CPDT-TPD-CPDT series, P8, which contains a higher number of donor units than the remaining members, shows the lowest HOMO and highest LUMO levels, leading to the largest electrochemical band gap $(2.3 \mathrm{eV})$ observed for all the polymers. Such tailoring of the energy levels by chemical synthesis would be advantageous for enhancing the open circuit voltage $\left(V_{\text {oc }}\right)$ in OPV devices.

The effect of BT and TPD acceptors on the energy levels can be further compared in PCPDT-BT $(\mathrm{HOMO}=-4.95 \mathrm{eV}$, $\left.E_{\mathrm{g}-\mathrm{ec}}=1.74 \mathrm{eV}\right)$, the double acceptor copolymer $\mathbf{P} 2 \quad(\mathrm{HOMO}=$

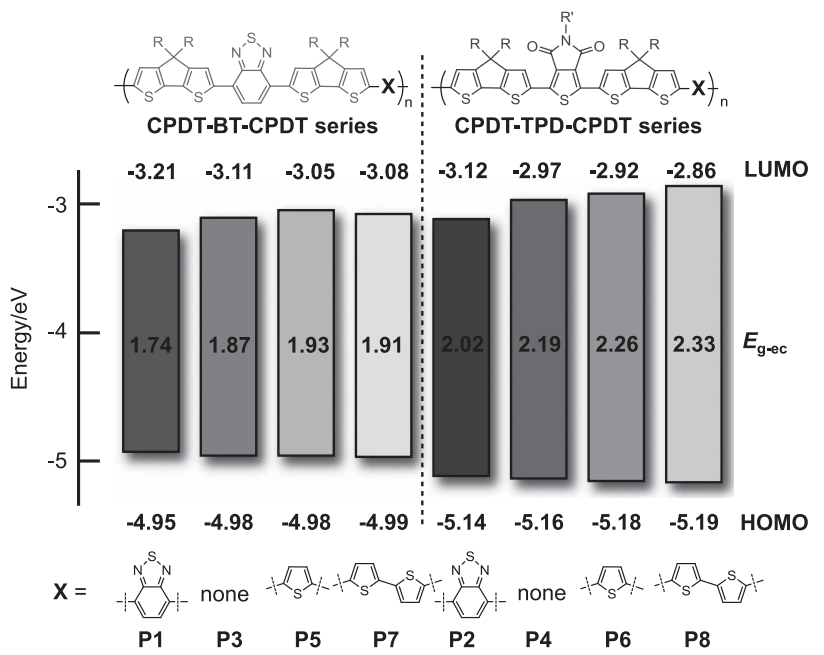

Figure 3 Energy diagrams for polymers P1-P8. A full color version of this figure is available at Polymer Journal online. $\left.-5.14 \mathrm{eV}, E_{\mathrm{g}-\mathrm{ec}}=2.02 \mathrm{eV}\right)$ and PCPDT-TPD $(\mathrm{HOMO}=-5.43 \mathrm{eV}$, $\left.E_{\text {g-ec }}=2.18 \mathrm{eV}\right) .{ }^{41}$ The presence of TPD in the alternating copolymers tends to result in a lower-energy HOMO level. This property is advantageous for generating a higher $V_{\mathrm{OC}}$ in OPVs, which is the primary weakness of devices based on $\mathrm{BT}$, while the copolymers containing BT units absorb sunlight between the red and near IR regions, thereby enhancing the short current density $\left(J_{\text {sc }}\right)$. P2 effectively combines the features of two acceptors and has the appropriate HOMO level and energy band gap derived from PCPDT-BT and PCPDT-TPD, respectively. This molecular design offers a fundamental working principle about how two different acceptors interact with each other in the same repeating unit in an alternating conjugated polymer.

OPV characteristics. Bulk heterojunction-type OPV devices were fabricated on glass substrates with an indium tin oxide/poly(3,4ethylenedioxythiophene):poly(styrene sulfonate) (ITO/PEDOT:PSS) anode. The active layer was spin cast from chlorobenzene solutions of the polymer mixed with $\mathrm{PC}_{71} \mathrm{BM}$ acceptor and a processing additive of ODT with a blend ratio of polymer/ $/ \mathrm{PC}_{71} \mathrm{BM} / \mathrm{ODT}=1: 3: 3$ at a concentration of $3 \mathrm{wt} \%$. Similar fabrication conditions were applied to all polymers to evaluate the effect of polymerization methodology on device performance. Preliminary OPV tests for P2 and P7 are shown in Figure 4, and characteristic OPV parameters for all polymers are summarized in Table 3.

The best PCE was observed for PCPDT-BT (P1 and P1-DA) $(\mathrm{PCE}=4.0 \%)$, which is consistent with our previous reports. ${ }^{35,62}$ Among the other polymers, the double acceptor polymer $\mathbf{P} 2$ exhibited a relatively high PCE of 3.0\%. These results suggest that a D-A ratio in the polymer backbone of 1:1 is favorable for a high PCE, because the low band gap can efficiently capture the long wavelengths of visible and near IR lights. Importantly, $\mathbf{P} 2$ shows a higher $V_{\mathrm{oc}}(0.68 \mathrm{~V})$ than P1 $(0.61 \mathrm{~V})$. This result is consistent with the lower HOMO levels of P2 $(\mathrm{HOMO}=-5.14 \mathrm{eV})$ compared with P1 $(\mathrm{HOMO}=-4.95 \mathrm{eV})$. A similar trend is observed in the other polymers: the TPD series shows a $V_{\mathrm{oc}} \sim 0.15 \mathrm{~V}$ higher than the BT series, which is close to the $0.2 \mathrm{eV}$ difference between the HOMO levels.

P7 showed a PCE (2.8\%) comparable with $\mathbf{P 2}$ despite possessing a wide band gap of $\sim 2.32 \mathrm{eV}$. This is probably the result of the higher charge transport ability obtained by the insertion of the bithiophene unit. ${ }^{23,37,68-70}$ Other polymers showed rather poor PCEs, possibly due to low $J_{\mathrm{sc}}$ values resulting from inefficient charge transport.

PCPDT-BT synthesized by direct arylation polymerization showed a similar OPV performance to that prepared using Suzuki polymerization (P1 and P1-DA in Table 1). ${ }^{62}$ The BT series resulting from direct arylation showed $V_{\mathrm{oc}}$ values comparable with those resulting from Suzuki or Stille coupling despite a moderate lower final performance (for example, $\mathrm{PCE}=2.8 \%$ for $\mathbf{P 7}$ and $1.8 \%$ for P7-DA) resulting from decreased $J_{\mathrm{sc}}$. The lower $J_{\mathrm{sc}}$ values for directly arylated polymers compared with those of conventionally coupled polymers is possibly the result of lower charge transport derived from minor structural defects, such as branching and CPDT-CPDT coupling. ${ }^{62,65}$ On the other hand, the TPD series resulting from direct arylation shows dramatically degraded OPV performance (for example, $\mathrm{PCE}=1.6 \%$ for P6 and $0.1 \%$ for P6-DA) in spite of the presence of a majority of correct chemical structures, as evidenced by ${ }^{1} \mathrm{H}$ NMR spectroscopy. The degradation of the PCE comes from not only the $J_{\mathrm{sc}}$ but also the $V_{\mathrm{oc}}$, which are supposedly the result of minor undesirable reactions, such as decomposition of the carbonyl group in the presence of base during polymerization. ${ }^{62,65}$ Consequently, direct arylation polymerization is potentially highly applicable for the synthesis of BT-containing 


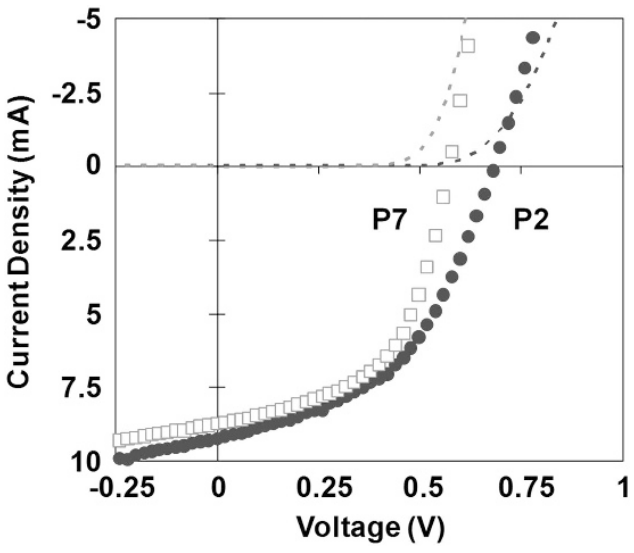

Figure 4 Current density-voltage characteristics of P2 and P7 blended with $\mathrm{PC}_{71} \mathrm{BM}$, measured under $\mathrm{AM} 1.5 \mathrm{G}$ illumination. A full color version of this figure is available at Polymer Journal online.

Table 3 OPV characteristics

\begin{tabular}{llclll}
\hline Polymer & Group & $\mathrm{J}_{s c}\left(\mathrm{~mA} \mathrm{~cm}^{-2}\right)$ & $\mathrm{V}_{\text {oc }}(\mathrm{V})$ & $F F$ & PCE (\%) \\
\hline P1 & BT/BT & 11.32 & 0.61 & 0.58 & 4.0 \\
P1-DA & BT/BT & $13.92^{\mathrm{a}}$ & $0.63^{\mathrm{a}}$ & $0.46^{\mathrm{a}}$ & $4.0^{\mathrm{a}}$ \\
P2 & TPD/BT & 9.25 & 0.68 & 0.47 & 3.0 \\
P2-DA & TPD/BT & 2.87 & 0.71 & 0.24 & 0.5 \\
P3 & BT/none & 3.65 & 0.49 & 0.41 & 0.7 \\
P4 & TPD/none & 3.21 & 0.67 & 0.57 & 1.2 \\
P5 & BT/thiophene & 6.47 & 0.58 & 0.39 & 1.5 \\
P5-DA & BT/thiophene & 2.33 & 0.60 & 0.44 & 0.6 \\
P6 & TPD/thiophene & 4.92 & 0.73 & 0.45 & 1.6 \\
P6-DA & TPD/thiophene & 0.27 & 0.61 & 0.46 & 0.1 \\
P7 & BT/bithiophene & 8.75 & 0.57 & 0.57 & 2.8 \\
P7-DA & BT/bithiophene & 6.37 & 0.64 & 0.44 & 1.8 \\
P8 & TPD/bithiophene & 3.32 & 0.78 & 0.42 & 1.1 \\
P8-DA & TPD/bithiophene & 1.33 & 0.66 & 0.47 & 0.4 \\
\hline
\end{tabular}

Abbreviations: FF, fill factor; $J_{\mathrm{SC}}$, short circuit current density; PCE, power conversion efficiency with mean of 8 devices; $V_{o c}$, open circuit voltage.

aFrom previous report. ${ }^{62}$

polymers, but further optimization of the polymerization procedure is necessary for carbonyl-containing polymers when they are used in OPVs.

Figure 5a shows the ultraviolet-visible spectra of thin films of $\mathbf{P 2}$ and $\mathrm{P} 7$ blended with $\mathrm{PC}_{71} \mathrm{BM}$ and $\mathrm{ODT}$ with a weight ratio of 1:3:3 on ITO glass substrates. A film of conventional bulk heterolayer of P3HT blended with $\mathrm{PC}_{61} \mathrm{BM}$ with a weight ratio of $1: 3$ on ITO glass substrate is also shown for comparison. $\mathbf{P} 2$ and $\mathbf{P 7}$ with $\mathrm{PC}_{71} \mathrm{BM}$ films showed wide-range absorption in the UV, visible and near IR regions without significant valleys, leading to subtractive color films, whereas the P3HT:PC ${ }_{61} \mathrm{BM}$ film had a strong absorption at $500 \mathrm{~nm}$, showing a clear orange-purple color. Photos of the film of P7:PC 71 BM:ODT on ITO glass substrate taken through a window and office background are shown in Figure 5b. Such subtractive color is advantageous when films are used for fabrication of transparent OPVs with transparent electrodes such as silver mesh. They can be used as architectural or building materials, including in windows and as wall paper.

\section{CONCLUSION}

Double acceptor copolymers comprising BT, TPD, and two CPDT units and a series of copolymers comprising CPDT-A-CPDT $(\mathrm{A}:$ acceptor $=\mathrm{BT}$ or TPD $)$ with different numbers of thiophene units
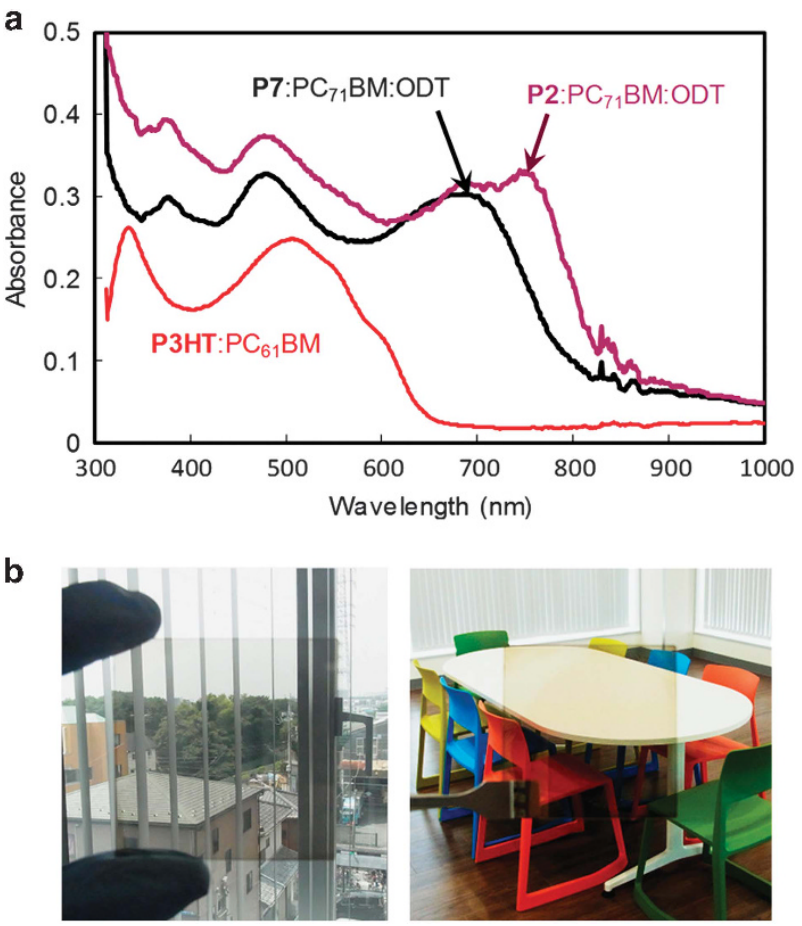

Figure 5 (a) Ultraviolet-visible spectra of thin films of P2, P7 and P3HT blended with $\mathrm{PC}_{71} \mathrm{BM}$ or $\mathrm{PC}_{61} \mathrm{BM}$ and $\mathrm{ODT}$ (1:3:3 weight ratio) on indium tin oxide (ITO) glass substrates (active layer thickness: $70 \mathrm{~nm}$ ). (b) Photos of the film of P7 blended with $\mathrm{PC}_{71} \mathrm{BM}$ and ODT (thickness ca., $70 \mathrm{~nm}$ ) on ITO glass substrate $\left(45 \times 45 \mathrm{~mm}^{2}\right)$ through a window and office background. ODT, 1,8-octanedithiol.

have been synthesized using combinations of Suzuki and Stille coupling, direct arylation and oxidative polymerization. We have tailored the absorption colors of the polymers, which is particularly essential in developing OPVs for use in building-integrated photovoltaics. The double acceptor copolymer exhibited hybridized features from both BT and TPD. With an increase in the number of electron donor units, the band gap increased for both the TPD and BT series as the result of weaker charge transfer between the donor and acceptor units. These results provide insight into the maximum conjugated length suitable for use as the building blocks of D-A conjugated polymers.

The OPV devices fabricated using the D-A alternating copolymers, including the double acceptor copolymers, in conjunction with the $\mathrm{PC}_{71} \mathrm{BM}$ acceptor showed higher OPV performance $(\mathrm{PCE}=3-4 \%)$ than other polymers. Interestingly, the double acceptor polymer with $\mathrm{PC}_{71} \mathrm{BM}$ showed a subtractive color, which is advantageous for the fabrication of transparent architectural OPVs. The OPV performance of BT-based copolymers synthesized by direct arylation was comparable or marginally lower compared with those prepared by conventional cross-coupling polymerizations, whereas TPD-based polymers synthesized by direct arylation showed a drastic degradation in OPV performance compared with the analogous polymers prepared by conventional methods. This is one important issue for the further improvement of direct arylation procedures.

While this study focused on systems comprising CPDT, BT, TPD and thiophene, the results provide researchers an insight into the effect of double acceptors, tailoring energy levels and the efficiency of directly arylated polymers in other material systems. 


\section{CONFLICT OF INTEREST}

The authors declare no conflict of interest.

\section{ACKNOWLEDGEMENTS}

We thank the National Science Council of Taiwan and LINTEC Corporation for financial support.

1 Krebs, F. C. Polymer solar cell modules prepared using roll-to-roll methods: knife-overedge coating, slot-die coating and screen printing. Sol. Energy Mater. Sol. Cells 93 465-475 (2009).

2 Krebs, F. C., Gevorgyan, S. A. \& Alstrup, J. A roll-to-roll process to flexible polymer solar cells: model studies, manufacture and operational stability studies. J. Mater. Chem. 19, 5442-5451 (2009).

3 Sondergaard, R., Hosel, M., Angmo, D., Larsen-Olsen, T. T. \& Krebs, F. C. Roll-to-roll fabrication of polymer solar cells. Mater. Today 15, 36-49 (2012).

4 Søndergaard, R. R., Hösel, M. \& Krebs, F. C. Roll-to-Roll fabrication of large area functional organic materials. J. Polym. Sci. B Polym. Phys. 51, 16-34 (2013).

5 Zhu, Z., Waller, D., Gaudiana, R., Morana, M., Mühlbacher, D., Scharber, M. \& Brabec, C. Panchromatic conjugated polymers containing alternating donor/acceptor units for photovoltaic applications. Macromolecules 40, 1981-1986 (2007).

6 Chen, H.-Y., Hou, J., Zhang, S., Liang, Y., Yang, G., Yang, Y., Yu, L., Wu, Y. \& Li, G. Polymer solar cells with enhanced open-circuit voltage and efficiency. Nat. Photon. 3 649-653 (2009).

7 Yuan, M.-C., Chiu, M.-Y., Liu, S.-P., Chen, C.-M. \& Wei, K.-H. A thieno[3,4-c]pyrrole4,6-dione-based donor-acceptor polymer exhibiting high crystallinity for photovoltaic applications. Macromolecules 43, 6936-6938 (2010).

8 Chu, T. Y., Lu, J., Beaupre, S., Zhang, Y., Pouliot, J. R., Wakim, S., Zhou, J., Leclerc, M., Li, Z., Ding, J. \& Tao, Y. Bulk heterojunction solar cells using thieno[3,4-c] pyrrole-4,6-dione and dithieno[3,2-b:2',3'-d]silole copolymer with a power conversion efficiency of 7.3\%. J. Am. Chem. Soc. 133, 4250-4253 (2011).

9 Polander, L. E., Pandey, L., Barlow, S., Tiwari, S. P., Risko, C., Kippelen, B., Brédas, J.-L. \& Marder, S. R. Benzothiadiazole-dithienopyrrole donor-acceptor-donor and acceptor-donor-acceptor triads: synthesis and optical, electrochemical, and chargetransport properties. J. Polym. Chem. C 115, 23149-23163 (2011).

10 Dou, L., Gao, J., Richard, E., You, J., Chen, C. C., Cha, K. C., He, Y., Li, G. \& Yang, Y. Systematic investigation of benzodithiophene- and diketopyrrolopyrrole-based lowbandgap polymers designed for single junction and tandem polymer solar cells. J. Am. Chem. Soc. 134, 10071-10079 (2012).

$11 \mathrm{He}$, Z., Zhong, C., Su, S., Xu, M., Wu, H. \& Cao, Y. Enhanced power-conversion efficiency in polymer solar cells using an inverted device structure. Nat. Photon. 6, 593-597 (2012).

12 Horie, M., Kettle, J., Yu, C.-Y., Majewski, L. A., Chang, S.-W., Kirkpatrick, J., Tuladhar, S. M., Nelson, J., Saunders, B. R. \& Turner, M. L. Cyclopentadithiophenebenzothiadiazole oligomers and polymers; synthesis, characterisation, field-effect transistor and photovoltaic characteristics. J. Mater. Chem. 22, 381-389 (2012).

13 Graham, K. R., Cabanetos, C., Jahnke, J. P., Idso, M. N., El Labban, A., Ngongang Ndjawa, G. O., Heumueller, T., Vandewal, K., Salleo, A., Chmelka, B. F., Amassian, A., Beaujuge, P. M. \& McGehee, M. D. Importance of the donor:fullerene intermolecular arrangement for high-efficiency organic photovoltaics. J. Am. Chem. Soc. 136, 9608-9618 (2014)

14 Liu, Y., Zhao, J., Li, Z., Mu, C., Ma, W., Hu, H., Jiang, K., Lin, H., Ade, H. \& Yan, H. Aggregation and morphology control enables multiple cases of high-efficiency polymer solar cells. Nat. Commun. 5, 5293 (2014).

15 Huang, J., Ie, Y., Karakawa, M., Saito, M., Osaka, I. \& Aso, Y. Enhanced Photovoltaic performance of amorphous copolymers based on dithienosilole and dioxocycloalkeneannelated thiophene. Chem. Mater. 26, 6971-6978 (2014).

16 Owczarczyk, Z. R., Braunecker, W. A., Oosterhout, S. D., Kopidakis, N., Larsen, R. E., Ginley, D. S. \& Olson, D. C. Cyclopenta[c]thiophene-4,6-dione-based copolymers as organic photovoltaic donor materials. Adv. Energy Mater. 4, 1301821-1301821 (2014).

17 Gu, C., Xiao, M., Bao, X., Han, L., Zhu, D., Wang, N., Wen, S., Zhu, W. \& Yang, R. Design, synthesis and photovoltaic properties of two $\pi$-bridged cyclopentadithiophenebased polymers. Polym. Chem. 5, 6551-6557 (2014).

18 Kim, J.-H., Park, J. B., Xu, F., Kim, D., Kwak, J., Grimsdale, A. C. \& Hwang, D.-H. Effect of $\pi$-conjugated bridges of TPD-based medium bandgap conjugated copolymers for efficient tandem organic photovoltaic cells. Energy Environ. Sci. 7, 4118-4131 (2014).

19 Kim, J.-H., Lee, M., Yang, H. \& Hwang, D.-H. A high molecular weight triisopropylsilylethynyl (TIPS)-benzodithiophene and diketopyrrolopyrrole-based copolymer for high performance organic photovoltaic cells. J. Mater. Chem. A 2, 6348 (2014).

20 Kim, J. S., Fei, Z., Wood, S., James, D. T., Sim, M., Cho, K., Heeney, M. J. \& Kim, J.-S Germanium- and silicon-substituted donor-acceptor type copolymers: effect of the bridging heteroatom on molecular packing and photovoltaic device performance. Adv. Energy Mater. 4, 1400527 (2014).

21 Schneider, A. M., Lu, L., Manley, E. F., Zheng, T., Sharapov, V., Xu, T., Marks, T. J., Chen, L. X. \& Yu, L. Wide bandgap OPV polymers based on pyridinonedithiophene unit with efficiency $>5 \%$. Chem. Sci. 6, 4860-4866 (2015).
22 Zhang, Z., Lin, F., Chen, H.-C., Wu, H.-C., Chung, C.-L., Lu, C., Liu, S.-H., Tung, S.-H., Chen, W.-C., Wong, K.-T. \& Chou, P.-T. A silole copolymer containing a ladder-type heptacylic arene and naphthobisoxadiazole moieties for highly efficient polymer solar cells. Energy Environ. Sci. 8, 552-557 (2015).

23 Osaka, I., Shimawaki, M., Mori, H., Doi, I., Miyazaki, E., Koganezawa, T. \& Takimiya, K. Synthesis, characterization, and transistor and solar cell applications of a naphthobisthiadiazole-based semiconducting polymer. J. Am. Chem. Soc. 134 3498-3507 (2012).

24 You, J., Dou, L., Yoshimura, K., Kato, T., Ohya, K., Moriarty, T., Emery, K., Chen, C. C., Gao, J., Li, G. \& Yang, Y. A polymer tandem solar cell with $10.6 \%$ power conversion efficiency. Nat. Commun. 4, 1446 (2013).

25 Dou, L., Chen, C.-C., Yoshimura, K., Ohya, K., Chang, W.-H., Gao, J., Liu, Y., Richard, E. \& Yang, Y. Synthesis of $5 \mathrm{H}$-dithieno[3,2-b:2',3'-d]pyran as an electron-rich building block for donor-acceptor type low-bandgap polymers. Macromolecules 46, 3384-3390 (2013).

26 Zhang, X., Gao, Y., Li, S., Shi, X., Geng, Y. \& Wang, F. Synthesis of poly(5,6-difluoro2,1,3-benzothiadiazole-alt-9,9-dioctyl-fluorene) via direct arylation polycondensation. J. Polym. Sci. A Polym. Chem. 52, 2367-2374 (2014).

27 Wang, X. \& Wang, M. Synthesis of donor-acceptor conjugated polymers based on benzo[1,2-b:4,5- $\left.b^{\prime}\right]$ dithiophene and 2,1,3-benzothiadiazole via direct arylation polycondensation: towards efficient $\mathrm{C}-\mathrm{H}$ activation in nonpolar solvents. Polym. Chem. 5, 5784-5792 (2014).

28 Lombeck, F., Komber, H., Gorelsky, S. I. \& Sommer, M. Identifying homocouplings as critical side reactions in direct arylation polycondensation. ACS Macro Lett. 3, 819-823 (2014).

29 Kowalski, S., Allard, S. \& Scherf, U. Scope and limitations of a direct arylation polycondensation scheme in the synthesis of PCPDTBT-type copolymers. Macromol. Rapid Commun. 36, 1061-1068 (2015).

30 Mühlbacher, D., Scharber, M., Morana, M., Zhu, Z., Waller, D., Gaudiana, R. \& Brabec, C. High photovoltaic performance of a low-bandgap polymer. Adv. Mater. 18 2884-2889 (2006).

31 Hwang, I. W., Soci, C., Moses, D., Zhu, Z., Waller, D., Gaudiana, R., Brabec, C. J. \& Heeger, A. J. Ultrafast electron transfer and decay dynamics in a small band gap bulk heterojunction material. Adv. Mater. 19, 2307-2312 (2007).

32 Peet, J., Kim, J. Y., Coates, N. E., Ma, W. L., Moses, D., Heeger, A. J. \& Bazan, G. C. Efficiency enhancement in low-bandgap polymer solar cells by processing with alkane dithiols. Nat. Mater. 6, 497-500 (2007).

33 Soci, C., Hwang, I. W., Moses, D., Zhu, Z., Waller, D., Gaudiana, R., Brabec, C. J. \& Heeger, A. J. Photoconductivity of a low-bandgap conjugated polymer. Adv. Funct. Mater. 17, 632-636 (2007).

34 Dennler, G., Scharber, M. C. \& Brabec, C. J. Polymer-fullerene bulk-heterojunction solar cells. Adv. Mater. 21, 1323-1338 (2009).

35 Kettle, J., Horie, M., Majewski, L. A., Saunders, B. R., Tuladhar, S., Nelson, J. \& Turner, M. L. Optimisation of PCPDTBT solar cells using polymer synthesis with Suzuki coupling. Sol. Energy Mater. Sol. Cells 95, 2186-2193 (2011).

36 Najari, A., Beaupré, S., Berrouard, P., Zou, Y., Pouliot, J.-R., Lepage-Pérusse, C. \& Leclerc, M. Synthesis and characterization of new thieno[3,4-c]pyrrole-4,6-dione derivatives for photovoltaic applications. Adv. Funct. Mater. 21, 718-728 (2011).

37 Guo, X., Ortiz, R. P., Zheng, Y., Kim, M. G., Zhang, S., Hu, Y., Lu, G., Facchetti, A. \& Marks, T. J. Thieno[3,4-c]pyrrole-4,6-dione-based polymer semiconductors: toward high-performance, air-stable organic thin-film transistors. J. Am. Chem. Soc. 133, 13685-13697 (2011).

38 Wakioka, M., Ichihara, N., Kitano, Y. \& Ozawa, F. A Highly efficient catalyst for the synthesis of alternating copolymers with thieno[3,4-c]pyrrole-4,6-dione units via direct arylation polymerization. Macromolecules 47, 626-631 (2014).

39 Kuwabara, J., Yamazaki, K., Yamagata, T., Tsuchida, W. \& Kanbara, T. The effect of a solvent on direct arylation polycondensation of substituted thiophenes. Polym. Chem. 6 891-895 (2015).

40 Li, Z., Tsang, S.-W., Du, X., Scoles, L., Robertson, G., Zhang, Y., Toll, F., Tao, Y., Lu, J. \& Ding, J. Alternating copolymers of cyclopenta[2,1-b;3,4- $b$ 'ddithiophene and thieno[3,4-c]pyrrole-4,6-dione for high-performance polymer solar cells. Adv. Funct. Mater. 21, 3331-3336 (2011).

41 Zhang, Y., Zou, J., Yip, H.-L., Sun, Y., Davies, J. A., Chen, K.-S., Acton, O. \& Jen, A. K. Y. Conjugated polymers based on $\mathrm{C}, \mathrm{Si}$ and $\mathrm{N}$-bridged dithiophene and thienopyrroledione units: synthesis, field-effect transistors and bulk heterojunction polymer solar cells. J. Mater. Chem. 21, 3895-3902 (2011).

42 Guo, X., Xin, H., Kim, F. S., Liyanage, A. D. T., Jenekhe, S. A. \& Watson, M. D. Thieno $[3,4-c]$ pyrrole-4,6-dione-based donor-acceptor conjugated polymers for solar cells. Macromolecules 44, 269-277 (2011).

43 MacNeill, C. M., Peterson, E. D., Noftle, R. E., Carroll, D. L. \& Coffin, R. C. A cyclopentadithiophene/thienopyrroledione-based donor-acceptor copolymer for organic solar cells. Synth. Met 161, 1137-1140 (2011).

44 Sonar, P., Foong, T. R. \& Dodabalapur, A. Synthesis of diketopyrrolopyrrole based copolymers via the direct arylation method for $\mathrm{p}$-channel and ambipolar OFETs. Phys. Chem. Chem. Phys. 16, 4275-83 (2014).

45 Nakanishi, T., Shirai, Y. \& Han, L. Synthesis and optical properties of photovoltaic materials based on the ambipolar dithienonaphthothiadiazole unit. J. Mater. Chem. A 3 4229-4238 (2015).

46 Lu, W., Kuwabara, J. \& Kanbara, T. Synthesis of 4,4'-dinonyl-2,2'-bithiazole-based copolymers via Pd-catalyzed direct C-H arylation. Polym. Chem. 3, 3217-3219 (2012).

47 Wakioka, M., Kitano, Y. \& Ozawa, F. A Highly efficient catalytic system for polycondensation of 2,7-dibromo-9,9-dioctylfluorene and 1,2,4,5-tetrafluorobenzene via direct arylation. Macromolecules 46, 370-374 (2013). 
48 Choi, S. J., Kuwabara, J. \& Kanbara, T. Microwave-assisted polycondensation via direct arylation of 3,4-ethylenedioxythiophene with 9,9-dioctyl-2,7-dibromofluorene. ACS Sustain. Chem. Eng. 1, 878-882 (2013).

49 Homyak, P. D., Tinkham, J., Lahti, P. M. \& Coughlin, E. B. Thieno[3,4-b]thiophene acceptors with alkyl, aryl, perfluoroalkyl, and perfluorophenyl pendants for donor-acceptor low bandgap polymers. Macromolecules 46, 8873-8881 (2013).

50 Rudenko, A. E., Wiley, C. A., Tannaci, J. F. \& Thompson, B. C. Optimization of direct arylation polymerization conditions for the synthesis of poly(3-hexylthiophene). J. Polym. Sci. A Polym. Chem. 51, 2660-2668 (2013).

51 Nakabayashi, K. \& Mori, H. Palladium-catalyzed Direct arylation approach to synthesize naphthalene bisimide-based low-band-gap polymers. Chem. Lett. 42, 717-718 (2013).

52 Kuramochi, M., Kuwabara, J., Lu, W. \& Kanbara, T. Direct arylation polycondensation of bithiazole derivatives with various acceptors. Macromolecules 47, 7378-7385 (2014).

53 Nohara, Y., Kuwabara, J., Yasuda, T., Han, L. \& Kanbara, T. Two-step direct arylation for synthesis of naphthalenediimide-based conjugated polymer. J. Polym. Sci. A Polym. Chem. 52, 1401-1407 (2014)

54 Rudenko, A. E., Khlyabich, P. P. \& Thompson, B. C. Random Poly(3-hexylthiophene-co3-cyanothiophene) copolymers via direct arylation polymerization (DArP) for organic solar cells with high open-circuit voltage. ACS Macro Lett. 3, 387-392 (2014).

55 Zhu, E., Ni, B., Zhao, B., Hai, J., Bian, L., Wu, H. \& Tang, W. Synthesis and photovoltaic characterization of dithieno[3,2-b:2', $\left.3^{\prime}-d\right]$ thiophene-derived narrowbandgap polymers. Macromol. Chem. Phys. 215, 227-234 (2014).

56 Luzio, A., Fazzi, D., Nübling, F., Matsidik, R., Straub, A., Komber, H., Giussani, E., Watkins, S. E., Barbatti, M., Thiel, W., Gann, E., Thomsen, L., McNeill, C. R., Caironi, M. \& Sommer, M. Structure-function relationships of high-electron mobility naphthalene diimide copolymers prepared via direct arylation. Chem. Mater. 26, 6233-6240 (2014).

57 Lu, W., Kuwabara, J., Kuramochi, M. \& Kanbara, T. Synthesis of bithiazole-based crystalline polymers via palladium-catalyzed direct $\mathrm{C}-\mathrm{H}$ arylation. J. Polym. Sci. A Polym. Chem. 53, 1396-1402 (2015).

58 Lombeck, F., Matsidik, R., Komber, H. \& Sommer, M. Simple synthesis of P(Cbz-altTBT) and PCDTBT by combining direct arylation with suzuki polycondensation of heteroaryl chlorides. Macromol. Rapid Commun. 36, 231-237 (2015).

59 Rudenko, A. E., Latif, A. A. \& Thompson, B. C. Minimization of the auxiliary reagent loading for direct arylation polymerization (DArP) of 2-bromo-3-hexylthiophene. J. Polym. Sci. A Polym. Chem. 53, 1492-1499 (2015).
60 Wang, X., Wang, K. \& Wang, M. Synthesis of conjugated polymers via an exclusive direct-arylation coupling reaction: a facile and straightforward way to synthesize thiophene-flanked benzothiadiazole derivatives and their copolymers. Polym. Chem. 6, 1846-1855 (2015)

61 Hayashi, S., Kojima, Y. \& Koizumi, T. Highly regioselective Pd/C-catalyzed direct arylation toward thiophene-based $\pi$-conjugated polymers. Polym. Chem. 6, 881-885 (2015).

62 Chang, S. W., Waters, H., Kettle, J., Kuo, Z. R., Li, C. H., Yu, C. Y. \& Horie, M. $\mathrm{Pd}$-catalysed direct arylation polymerisation for synthesis of low-bandgap conjugated polymers and photovoltaic performance. Macromol. Rapid Commun. 33 , 1927-1932 (2012)

63 Chang, S.-W., Waters, H., Kettle, J. \& Horie, M. Cyclopentadithiophenebenzothiadiazole oligomers: Synthesis via direct arylation, X-ray crystallography, optical properties, solution casted field-effect transistor and photovoltaic characteristics. Org. Electron. 13, 2967-2974 (2012).

64 Chang, S.-W., Kettle, J., Waters, H. \& Horie, M. Cyclopentadithiophenebenzothiadiazole copolymers with permutations of repeating unit length and ratios; synthesis, optical and electrochemical properties and photovoltaic characteristics. RSC Adv. 5, 107276-107284 (2015).

$65 \mathrm{Li}$, C.-H., Kettle, J. \& Horie, M. Cyclopentadithiophene-naphthalenediimide polymers; synthesis, characterisation, and n-type semiconducting properties in field-effect transistors and photovoltaic devices. Mater. Chem. Phys. 144, 519-528 (2014).

66 Beaujuge, P. M., Ellinger, S. \& Reynolds, J. R. The donor-acceptor approach allows a black-to-transmissive switching polymeric electrochrome. Nat. Mater. 7, 795-799 (2008)

67 Beaujuge, P. M., Tsao, H. N., Hansen, M. R., Amb, C. M., Risko, C., Subbiah, J., Choudhury, K. R., Mavrinskiy, A., Pisula, W., Bredas, J. L., So, F., Mullen, K. \& Reynolds, J. R. Synthetic principles directing charge transport in low-band-gap dithienosilole-benzothiadiazole copolymers. J. Am. Chem. Soc. 134, 8944-8957 (2012).

68 Usta, H. Lu, G. Facchetti, A. \& Marks, T. J. Dithienosilole- and dibenzosilolethiophene copolymers as semiconductors for organic thin-film transistors. J. Am. Chem. Soc. 128, 9034-9035 (2006).

69 Usta, H., Facchetti, A. \& Marks, T. J. Air-stable, solution-processable n-channel and ambipolar semiconductors for thin-film transistors based on the indenofluorenebis (dicyanovinylene) core. J. Am. Chem. Soc. 130, 8580-8581 (2008).

70 Liang, F., Lu, J., Ding, J., Movileanu, R. \& Tao, Y. Design and synthesis of alternating regioregular oligothiophenes/benzothiadiazole copolymers for organic solar cells. Macromolecules 42, 6107-6114 (2009).

Supplementary Information accompanies the paper on Polymer Journal website (http://www.nature.com/pj) 